\title{
Influence of the soil electrical conductivity in the area of the underground pipeline on energy efficiency of the cathodic protection
}

\author{
Vladimir Kiselev ${ }^{1 *}$, Alexandr Kalyutik ${ }^{1}$, and Evgenij Rouzich ${ }^{1}$ \\ ${ }^{1}$ Peter the Great St. Petersburg Polytechnic University, 29 Politekhnicheskaya street, 195251, Saint \\ Petersburg, Russia.
}

\begin{abstract}
In this paper we consider main factors which have an influence on energy efficiency of the cathodic protection and analyze them. Cathodic protection is defined as the ratio of the electrical conductivity of electrolyte, which surrounds the underground (underwater) metal construction (pipeline) and its polarization resistance. The obtained results are correct first of all for the case of presence of modern qualitative insulation, which possess high dielectric properties and is made of, for example, polymers or its' composition and is meant to be used for protection against electrochemical corrosion of the underground pipelines
\end{abstract}

\section{The problem statement}

At development and production of equipment, constructions and buildings of various types and functions its resistances to corrosion are of essence [1-10]. In the recent times for protection the underground metal constructions (UMC) from corrosion, combined methods, including combined use of coatings and electrochemical protection are increasingly often used [11-13]. The existing normative documents, including Russian State Standards GOST 9.602 - 2005 [14] and GOST R 51164 - 98 [15] require providing of a certain level of polarization protection potential, which is measured with respect to saturated copper-sulfate electrode of comparison. So, for example, for steel underground pipelines the range of the allowable values is oscillated between 0.85 and $1.15 \mathrm{~V}$. At the same time it is known that achievement of the declared value of the polarization potential is practically impossible without a certain value of the ohmic potential drop in electrolyte, which surrounds the electrode being polarized. Consequently, for designing efficient systems of cathodic protection one should take this fact into account. Unfortunately, the existing normative documents, including RD 153-39.4-091-01 [16] do not take this problem into consideration at all. This paper is an attempt to solve this problem aiming at the most economicallyfeasible providing of the required protection potential according to Russian State Standard GOST $9.602-2005$ [14] for the total length of the pipeline protection zone.

* Corresponding author: kis_vg@mail.ru 


\section{Basic principles for cathodic protection from corrosion of the underground metal constructions}

Cathodic protection from corrosion by the applied current (further referred as cathodic protection or electrochemical protection) in case of UMC is often used for protection from the soil corrosion, as well as for protection from corrosion which is caused by AC and DC earth currents. The alternating-current rectifiers with special units which provide automatic regulation of the electrical characteristics of the electrochemical protection are now often used as modern devices for cathodic protection. As the main parameter, which should be adjusted one often choose electrochemical potential of the protected construction in relation to soil. At the absence of special aggressive conditions it is sustained within the limits from 0.85 to $1.15 \mathrm{~V}$.

We assume that all requirements form DIN 30676 [17] (high longitudinal conductivity of pipelines; absence of contacts with grounded constructions) are fulfilled, so we can perform calculations of the major parameters of the cathodic protection. As an object for protection we will choose a separate pipeline, which is located in soil and has a qualitative (for example, polyethylene) anti-corrosive coating.

Basic principles of the cathodic and galvanic protections are well-studied, and its features, connected with various properties of the dielectric insulation of the pipeline are presented in early works $[19,20]$. We will use some data from this works for estimation of influence of the specific resistance of the soil, in which the pipeline is located on the efficiency of the UMC cathodic protection unit. We assume that the UMC (pipeline) is characterized by the following parameters: material (steel) specific resistance $\rho_{\mathrm{s}}$ is $0.18 *$ $10^{-6} \mathrm{Ohm} \cdot \mathrm{m}$; external pipeline diameter $d$ is $321 \mathrm{~mm} ; s$ is pipeline wall width $(s=6 \mathrm{~mm})$; anti-corrosive coating is made from polyethylene. According to the handbook data [20], the specific protective current $j_{s}$ in this case for pipelines located in soil, varies within the limits from $10^{-5}$ to $10^{-6} \mathrm{~A} / \mathrm{m}^{2}$.

Basing on these data and according to the technique described in [18] we will calculate basic parameters of the cathodic protection of the considered pipeline for protection current density $j_{\mathrm{s}}$ equal to $10^{-5} \mathrm{~A} / \mathrm{m}^{2}$.

We will represent the relation between protective pipeline area and total protective current, calculated using the formulas from [20] and protective current density and numerical characteristics of the object being protected in tabular form (Table 1).

Table 1. Basic parameters, which characterize the pipeline protection area

\begin{tabular}{|c|c|c|}
\hline$J_{s}, A / m^{2}$ & $2 L, k m$ & $I_{0}, A$ \\
\hline $10^{-5}$ & 89.443 & 0.902 \\
\hline
\end{tabular}

As it is seen from this Table, the chosen density of protection current $\left(j_{\mathrm{s}}\left[A / \mathrm{m}^{2}\right]\right)$ denotes the length of the pipeline cathodic protection area $(2 L[\mathrm{~km}])$ and the pipeline protection current $\left(I_{0}[A]\right)$. However, according to the formulas, both the protection area and the total protection current don't depend on the specific resistance of the soil. Actually, this dependence exists, but it is "hidden" in the parameter called "protection current density". Further we will consider how this value is denoted and its influence on the cathodic protection efficiency. 


\section{Determination of the influence of the specific resistance of the soil on the efficiency of the cathodic protection at the pipeline location area.}

First stage of designing of any electrochemical protection consists in determination of the necessary density of the protection current $J_{s}$. It is obvious that expenses for the electrochemical protection will decrease with decreasing of the protection current. Experimental investigations of the necessary value of protection current are always accompanied by measurement of the UMC polarization potential, and its value doesn't depend on the ohmic drop of potential in electrolyte. However, measurements of this parameter are always associated with elimination of the ohmic potential drop at the defect, which is already a function of the specific resistance of the soil, defect dimension and shape, ant the coating width. Similar problem also arises at performing of the cathodic protection itself. For this case, taking into account that the intrinsic conductivity of the dielectric coating is very low in comparison with the defect conductivity which is proved, in particular, in the works [21,22], one should use the following formula for calculation the resistance of the defect of a round shape [20]:

The formula which denotes the polarization defect resistance is:

$$
R_{\mathrm{p}}=\frac{r_{\mathrm{p}}}{A}
$$

where $r_{\mathrm{p}}$ is specific polarization resistance of metal surface near the cover defect (according to [20] $r_{\mathrm{p}}=1 \mathrm{Ohm} \cdot \mathrm{m}^{2}$ ); $A$ is cover defect area.

The formula which defines resistance of a cover layer, arising on metal surface during the process of cathode protection unit operation is:

$$
R_{\mathrm{D}}=\frac{r_{\mathrm{d}}}{A}
$$

where $r_{\mathrm{d}}$ is specific resistance of the cover layer, which arises at long operation of the cathodic protection unit.

Formula which denotes soil resistance in a round shape defect is:

$$
R_{\mathrm{F}}=\frac{\rho l}{A},
$$

where, $\rho$ is specific resistance of the soil, and $l$ is the width of the pipeline dielectric coating.

Formula which denotes spreading resistance in a round shape defect is:

$$
R_{\mathrm{S}}=\frac{\rho}{2 a}
$$

where $a$ is diameter of round shape defect.

It is obvious that in this case the total resistance of defect $R$ is a sum of polarized $R_{\mathrm{p}}$ and ohmic $R_{\mathrm{G}}$ resistances and can be calculated using the following formula:

$$
R=R_{\mathrm{p}}+R_{\mathrm{G}}
$$

Where $R_{\mathrm{G}}$ denotes ohmic potential drop in a defect and can be calculated using the following equation:

$$
R_{\mathrm{G}}=R_{\mathrm{D}}+R_{\mathrm{F}}+R_{\mathrm{S}}
$$

At this we should note that the coating layer resistance $R_{\mathrm{D}}$ which is formed at relatively long-lasting operation of the cathodic protection unit, by its definition, is weakly dependent on the specific resistance of the soil. Consequently, within the stated theme of the work this parameter may not be taken into account, when considering the case that the system is in the condition with no coating layer. This situation may occur both at short operating time of the cathodic protection, and in acid soils, where formation of coating layer is rather difficult.

For determination of influence of specific resistance of the soil in the area of pipeline on the efficiency of the cathodic protection unit in direct current (without taking into account the losses in transmitter) one can use the following model representations: 
We assume that the pipeline has a dielectric (for example, polyethylene) coating of 5 $\mathrm{mm}$ width (polyethylene specific resistance $\rho_{\mathrm{D}}$ is about $10^{18} \mathrm{Ohm} \cdot \mathrm{cm}$ ). Laboratory and practical measurements show [21] that polyethylene specific resistance decreases by 2-3 orders of magnitude and is about $10^{15} \mathrm{Ohm} \cdot \mathrm{cm}$ when it is buried in ground for a long time. We denote this value by $\rho_{\mathrm{u}}$.

We assume that identical round shape defects are located at the pipeline starting from the point of current drainage.

We assume that each defect has an area of $6.25 \mathrm{~cm}^{2}$ i.e. it is equal to area of potential controller which is used for polarization potential measurements according to Russian State Standard GOST $9.602-2005$ [14].

We assume that specific resistance of the soil in the area of the pipeline location varies from 0 to $100 \mathrm{Ohm} \cdot \mathrm{m}$.

Basing on these conditions, we will calculate the cathodic protection parameters, namely the pipeline insulation resistance at the protection length $89.443 \mathrm{~km}$, which corresponds to the protection current density $j_{\mathrm{s}}=10^{-5} \mathrm{~A} / \mathrm{m}^{2}$ and its total value $I_{0}=$ $0.902 A$. It is known that insulation resistance in this case will be expressed by the following formula:

$$
R_{\text {ins }}=\rho_{\mathrm{u}} \frac{1}{2 \pi d L}
$$

We put numerical values in it and perform the calculations. We obtain that $R_{\text {ins }}=$ $5.55 \cdot 10^{9} \mathrm{Ohm}$ which, as we will see further, is significantly more than the resistances of the insulation defects. Consequently, this value cannot be taken into account in the subsequent calculations.

We calculate the polarization resistance of the defect $R_{\mathrm{p}}$ depending on the specific resistance of the soil using the formula (1). We put numerical values, which we denoted earlier into this formula and obtain that polarization resistance doesn't depend on the soil resistance, i.e. remains constant at variation of this parameter (according to our calculation for one defect of the chosen dimensions it is equal to: $R_{\mathrm{p}}=1600 \mathrm{Ohm}$ ). We put these values into the Table 2 .

We calculate the polarization resistance of the defect $R_{\mathrm{F}}$ depending on the specific resistance of the soil using the formula (3). We put numerical values, which we denoted earlier, into this formula and perform calculations. We put the obtained values into the Table 2 .

We calculate the spreading resistance of the defect $R_{\mathrm{S}}$ depending on the specific resistance of the soil using the formula (4). We put numerical values, which we denoted earlier, into this formula and perform calculations. We put these values into the Table 2 .

We will calculate the ohmic drop of potential in a defect $R_{\mathrm{G}}$ using the formula (6), This formula will be the following in our conditions, i.e. taking into account that the resistance of the coating layer, which arises at long-lasting operation of the cathodic protection unit is equal to $0\left(R_{\mathrm{D}}=0\right)$ :

$$
R_{\mathrm{G}}=R_{\mathrm{F}}+R_{\mathrm{S}}
$$

We put numerical values, which we denoted earlier, into the formula (8) and perform calculations. We put the obtained values into the Table 2 .

We will calculate the average polarization resistance of the defect over the total protection area of the UMC on the basis of general conditions for the pipeline protection zone determination (copper-sulfate potential varies from $-0.85 \mathrm{~V}$ to $-1.15 \mathrm{~V}$ according to copper-sulfate electrode of comparison). However, in these conditions the specific polarization resistance $r_{\mathrm{p}}$ varies from its minimum value $1 \mathrm{Ohm} \cdot \mathrm{m}^{2}$ at the periphery of the protection zone to its maximum possible value $2 \mathrm{Ohm} \cdot \mathrm{m}^{2}$ near the drainage point. It is obvious that average value of the polarization resistance for the whole UMC protection area in this case is equal to $1.5 \mathrm{Ohm} \cdot \mathrm{m}^{2}$. We put this value of the specific polarization resistance 
together with the defect area (A) into the formula (1) and perform the calculations. We put the obtained values $R_{\text {p.av }}$ into the Table 2 .

One can perform calculations of the amount of the round-shape defects for the protection zone of the 89.443 length basing on the protection current $I_{0}=0.902 \mathrm{~A}$, density of the protection (polarization) current in a defect $j_{\mathrm{p}}\left[\mathrm{A} / \mathrm{m}^{2}\right]$ equal to $0.3 \mathrm{~A} / \mathrm{m}^{2}$ and the chosen area of one defect $\left(A=6.25 \mathrm{~cm}^{2}\right)$ using the following formula:

$$
n=\frac{I_{0}}{j_{\mathrm{p}} A}
$$

We put numerical values into the formula (7) and perform the calculations. We put the obtained value $n=4811$ into the Table 2 .

The obtained amount of the defects due to its parallel connection allows one to calculate both the average polarization $\overline{R_{\text {p.av }}}$ and total ohmic resistances $\overline{R_{\mathrm{G}}}$ of the pipeline defects. We will do this be dividing the corresponding values on the amount of defects and put the obtained result in Table 2.

We will calculate the power $P_{\mathrm{PDT}}$ produced at polarization resistance of the pipelines using the following formula:

We put these results in Table 2 .

$$
P_{\mathrm{PDT}}=I_{0}^{2} \overline{R_{\mathrm{p} . \mathrm{av}}}
$$

We will calculate the power $P_{\mathrm{FST}}$, which is produced at soil resistance in pipeline defects using the well-known formula:

We put these results in Table 2 .

$$
P_{\mathrm{FST}}=I_{0}^{2} \overline{R_{\mathrm{G}}}
$$

\subsection{Calculation of power in dc current circuit of cathodic protection unit which is spent at ohmic resistance of cable.}

According to handbook data [23] we assume that potential drop in cable of dc current circuit is $2 \mathrm{~V}$ and we put these data in Table 2 . We will calculate power $P_{\mathrm{k}}$, which is produced at cable resistance in direct current circuit of cathodic protection unit using the formula:

We put these results in Table 2 .

$$
P_{\mathrm{k}}=I_{0} U_{\mathrm{K}}
$$

\subsection{Calculation of power in direct current circuit of cathodic protection unit, which is spent at spreading resistance of anodic protection.}

We assume that spreading resistance of anodic protection $R_{\mathrm{A}}$ in each case is $1 \mathrm{Ohm}$ and we put these data in Table 2 . We will calculate the power $P_{\mathrm{A}}$, which is produced at spreading resistance of anodic protection, using the well-known formula:

We put these results in Table 2 .

$$
P_{\mathrm{A}}=I_{0}^{2} R_{\mathrm{A}}
$$

We will calculate the efficiency of the cathodic protection at direct current $\eta_{\mathrm{i}}$ depending on the specific resistance of the soil in the area of the pipeline location using the tradition expression for this case:

$$
\begin{gathered}
\eta_{\mathrm{i}}=\frac{P_{\mathrm{PDT}}}{P_{\mathrm{tr}}} \\
P_{\text {пр }}=P_{\mathrm{PDT}}+P_{\mathrm{FST}}+P_{\mathrm{k}}+P_{\mathrm{A}}
\end{gathered}
$$

$P_{\text {tr }}$ denotes necessary power of cathode protection transmitter at direct current. We put these results in Table 2 . 
Table 2. Technical parameters of the cathodic protection imposed by the pipeline current, which are denoted at various values of the specific resistance of the soil for the UMC location area.

\begin{tabular}{|c|c|c|c|c|c|c|c|c|c|c|c|}
\hline$\rho, \mathrm{Om} \cdot \mathrm{m}$ & 0 & 10 & 20 & 30 & 40 & 50 & 60 & 70 & 80 & 90 & 100 \\
\hline$R_{p}, \mathrm{kOhm}$ & 1.60 & 1.60 & 1.60 & 1.60 & 1.60 & 1.60 & 1.60 & 1.60 & 1.60 & 1.60 & 1.60 \\
\hline$R_{F}, \mathrm{kOhm}$ & 0 & 0.08 & 0.160 & 0.240 & 0.320 & 0.400 & 0.480 & 0.560 & 0.640 & 0.720 & 0.800 \\
\hline$R_{S}, \mathrm{kOhm}$ & 0 & 0.177 & 0.355 & 0.532 & 0.709 & 0.887 & 1.063 & 1.241 & 1.418 & 1.596 & 1.773 \\
\hline$R_{G}, \mathrm{kOhm}$ & 0 & 0.257 & 0.515 & 0.772 & 1.029 & 1.287 & 1.544 & 1.801 & 2.058 & 2.316 & 2.573 \\
\hline$R_{p . a v}, \mathrm{kOhm}$ & 2.4 & 2.4 & 2.4 & 2.4 & 2.4 & 2.4 & 2.4 & 2.4 & 2.4 & 2.4 & 2.4 \\
\hline$n, \mathrm{pcs}$ & 4811 & 4811 & 4811 & 4811 & 4811 & 4811 & 4811 & 4811 & 4811 & 4811 & 4811 \\
\hline$\overline{R_{p . a v}}, \mathrm{Ohm}$ & 0.499 & 0.499 & 0.499 & 0.499 & 0.499 & 0.499 & 0.499 & 0.499 & 0.499 & 0.499 & 0.499 \\
\hline$\overline{R_{G}}, \mathrm{Ohm}$ & 0 & 0.053 & 0.107 & 0.160 & 0.214 & 0.268 & 0.321 & 0.374 & 0.428 & 0.481 & 0.535 \\
\hline $\mathrm{P}_{P D T}, W$ & 0.406 & 0.406 & 0.406 & 0.406 & 0.406 & 0.406 & 0.406 & 0.406 & 0.406 & 0.406 & 0.406 \\
\hline $\mathrm{P}_{F S T}, W$ & 0 & 0.043 & 0.087 & 0.130 & 0.174 & 0.218 & 0.261 & 0.304 & 0.348 & 0.392 & 0.435 \\
\hline$U_{\mathrm{K}}, \mathrm{V}$ & 2 & 2 & 2 & 2 & 2 & 2 & 2 & 2 & 2 & 2 & 2 \\
\hline$P_{k}, W$ & 1.804 & 1.804 & 1.804 & 1.804 & 1.804 & 1.804 & 1.804 & 1.804 & 1.804 & 1.804 & 1.804 \\
\hline$R_{\mathrm{A}}, \mathrm{Ohm}$ & 1 & 1 & 1 & 1 & 1 & 1 & 1 & 1 & 1 & 1 & 1 \\
\hline$P_{A}, W$ & 0.814 & 0.814 & 0.814 & 0.814 & 0.814 & 0.814 & 0.814 & 0.814 & 0.814 & 0.814 & 0.814 \\
\hline$P_{t r}, W$ & 3.024 & 3.077 & 3.111 & 3.154 & 3.198 & 3.242 & 3.285 & 3.328 & 3.372 & 3.416 & 3.459 \\
\hline$\eta_{i}, \%$ & 13.4 & 13.2 & 13.1 & 12.9 & 12.7 & 12.5 & 12.4 & 12.2 & 12.0 & 11.9 & 11.7 \\
\hline
\end{tabular}

\section{Analysis of results}

The calculation results from Table 2 show a stable tendency for growth of efficiency of cathodic protection at protection the underground (underwater) pipelines with decrease of specific resistance of the soil (electrolyte) in the area of the pipeline location. However, increase in efficiency of the cathodic protection system at direct current for the accepted conditions is just some percents, which is neglible from the economical point of view. At the same time at decreasing $U_{\mathrm{K}}$ and $R_{\mathrm{A}}$, which can be really achieved, increase in $\eta_{\mathrm{i}}$ might be ten percents and even more. In this case, especially for urban conditions, where the protection current if often $40 \mathrm{~A}$ and more and the amount of units, for example at the territory of Saint-Petersburg is more than 3000, the economical effect from the rational choice of the pipeline route might be rather noticeable. Besides this, growth of specific resistance of the soil in the area of the pipeline location increases the absolute value of the potential gradient at the UMC location area. This, according to the paragraph 4.7 of the Russian State Standard GOST 9.602 - 2005 [14] increases the danger of the stray currents impact on the adjacent underground metal constructions.

\section{Conclusions}

1. We have considered the influence of the specific resistance of the soil in the area of the underground pipeline location of the efficiency of the cathodic protection unit at direct current $\eta_{i}$, which is denoted by the ratio between the pipeline polarization resistance and the sum of ohmic resistances at direct currents of the cathodic protection system.

2. It was shown that at fixed geometrical parameters of defects in the presence of modern dielectric (for example, polyethylene) coating with growth of specific resistance of the soil one observe decrease of $\eta_{i}$, which is accompanied by growth of a dangerous impact of stray currents on the adjacent underground metal constructions. 


\section{References}

1. Z. Bonić, G.T. Ćurčć, M. Trivunić, N. Davidović, N. Vatin, Procedia Engineering 117(1), 424-435 (2015)

2. V.G. Kiselev, V.V. Sergeev, E.N. Rouzich, Corrosion Reviews 35(1), 47-51 (2017)

3. M. Gravit, O. Zybina, A. Vaititckii, A. Kopytova, IOP Conference Series: Earth and Environmental Science 90(1), 012103 (2017)

4. M. Beliaev, A. Semenov, S. Semenov, A. Benin, MATEC Web of Conferences 73, 04010 (2016)

5. C. Apostolopoulos, A. Drakakaki, A. Apostolopoulos, T. Matikas, A.I. Rudskoi, G. Kodzhaspirov, Materials Physics and Mechanics 30(1), 1-19 (2017)

6. K. Strogonov, A. Fedyukhin, T. Stepanova, O. Derevianko, O., Advances in Intelligent Systems and Computing 692, 1024-1035 (2018)

7. A. Yu. Baimakov, S.Yu. Petrovich, V.A. Lipin, A.L. Shahmin, R.A. Seytenov, TMS Light Metals 2015-January, 387-391 (2015)

8. A.A. Kazakov, A. Shakhmatov, R., Badrak, E. Kolpishon, Materials Performance and Characterization 6(3), 271-280 (2017)

9. E.A. Loktionova, D.R. Miftakhova, Magazine of Civil Engineering 76(8), 214-224 (2017)

10. V. Maslak, N. Nasonkina, V. Sakhnovskaya, M. Gutarova, S. Antonenko, D. Nemova, Procedia EngineeringVolume 117(1), 985-994 (2015)

11. S. Bogdanov, M. Sychov, L. Lebedev, S. Mjakin, M. Gravit, Procedia Engineering 165, 1579-1586 (2016)

12. S.Y. Kondrat'ev, O.V. Shvetsov, Metal Science and Heat Treatment 60(1-2), 32-38 (2018)

13. T.I. Bobkova, B.V. Farmakovskii, S.P. Bogdanov, Inorganic Materials: Applied Research 7(6), 855-862 (2016)

14. Russian State Standard GOST 9.602 - 2005. Uniform system of protection from corrosion and ageing; Underground constructions; General requirements for protection from corrosion, 55 (2006)

15. Russian State Standard GOST 51164-98. Steel main pipelines. General requirements for anti-corrosion protection, 41 (1998)

16. RD 153-39.4-091-01 Instruction for protection of city underground pipelines against corrosion, 240 (2002)

17. DIN 30 676. Planung und Anwendung des kathodischen Korrosionsschutzes für den Außenschütz.

18. V.G. Kiselev, St. Petersburg State Polytechnical University Journal 4, 135, 111-116 (2011)

19. V.G. Kiselev, St. Petersburg State Polytechnical University Journal 3, 130, 75-80 (2011)

20. W. Baeckmann, Taschenbuch für den kathodischen Korrosionsschutz. Essen.: VulkanVerlag, 1996. 339 p.

21. W. Baeckmann und W. Schwenk, Handbuch des kathodischen Korrosionsschutzes. Weinheim.: Verlag Chemie. 1980. 465 p.

22. V.G. Kiselev, St. Petersburg State Polytechnical University Journal 4-1, 183, 93-99 (2013) 
23. Bette Ulrich, Taschenbuch für den kathodischen Korrosionsschutz. Ulrich Bette, Wolfgang Vesper Essen.: Vulkan-Verlag, 2005. 367 P. 